\title{
Performance Analysis of a Multiple Micro-Jet Impingements Cooling Model
}

\author{
A. Husain”, a, N.A. Al-Azria, A. Samadb, K.Y. Kim \\ *a Department of Mechanical and Industrial Engineering, Sultan Qaboos University, Muscat, Oman. \\ ${ }^{b}$ Department of Ocean Engineering, Indian Institute of Technology, Madras, Chennai, India. \\ c Department of Mechanical Engineering, Inha University, Incheon, Republic of Korea.
}

Received 14 April 2014; Accepted 21 October 2015

\begin{abstract}
The present study investigates the thermal performance of a multiple micro-jet impingements model for electronics cooling. The fluid flow and heat transport characteristics were investigated for steady incompressible laminar flow by solving three-dimensional (3D) Navier-Stokes equations. Several parallel and staggered micro-jet configurations (ie. inline $2 \times 2,3 \times 3$ and $4 \times 4$ jets, and staggered five-jet and 13-jet arrays with the jet diameter to the channel height ratios from $0.25-0.5)$ were analyzed at various flow rates for the maximum temperature rise, pressure drop, heat-transfer coefficient, thermal resistance, and pumping power characteristics. The parametric investigation was carried out based on the number of jets and the jet diameters at various mass flow rates and jet Reynolds numbers. Temperature uniformity and coefficient of performance were evaluated to find out the trade-off among the various designs investigated in the present study. The maximum temperature rise and the pressure drop decreased with an increase in the number of jets except in the case of staggered five-jet array. A higher temperature uniformity was observed at higher flow rates with a decrease in the coefficient of performance. The performance parameters, such as thermal resistance and pumping power, showed a conflicting nature with respect to design variables (viz. jet diameter to stand-off ratio and interjet spacing or number of jets) at various Reynolds numbers within the laminar regime.
\end{abstract}

Keywords: Jet impingement, Thermal resistance, Pumping power, Temperature uniformity, Heat transfer coefficient, Coefficient of performance.

$$
\text { تحليل الأداء لنموذج التبريد بالارتطام متعدد النافثات الدقيقة }
$$

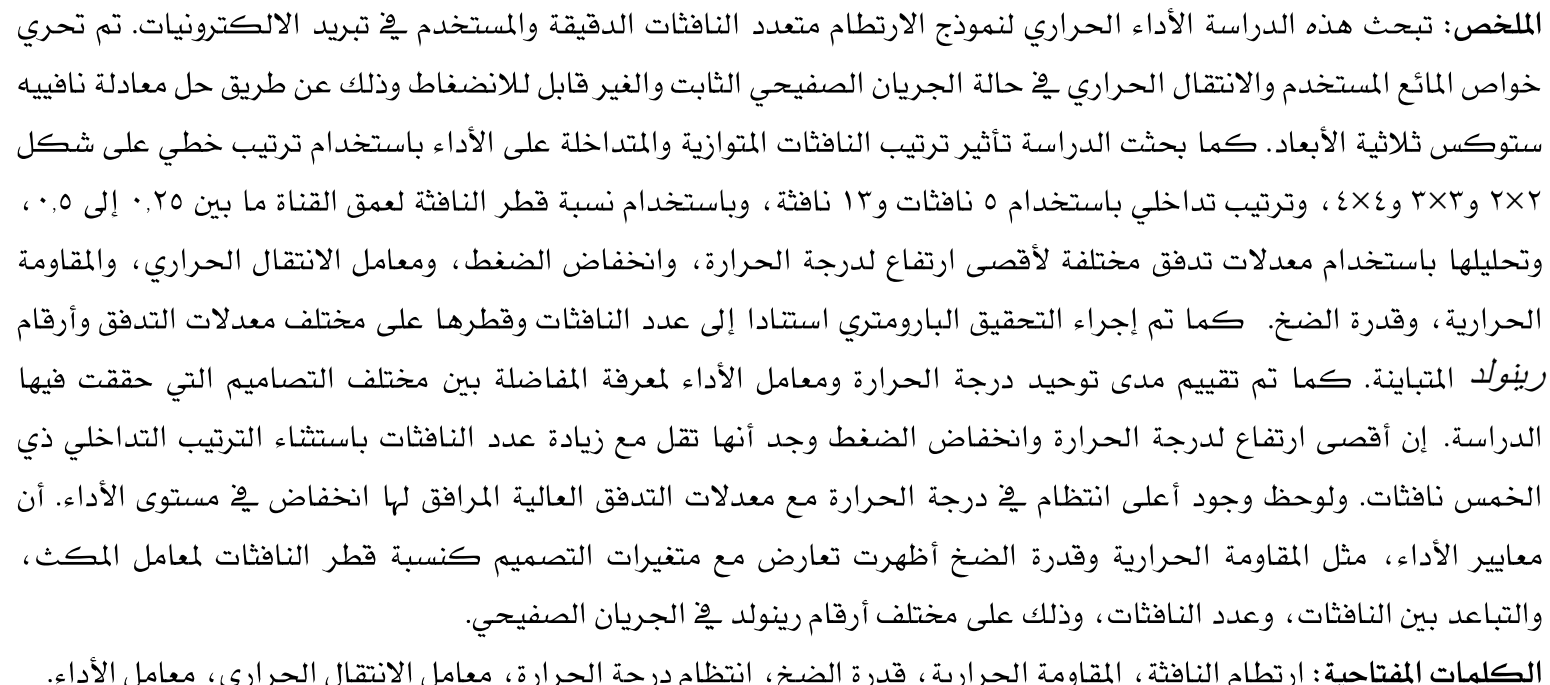

*Corresponding author's e-mail: afzal19@squ.edu.om 


\section{Nomenclature}



\section{Greek symbols}

$\begin{array}{ll}\mu & \text { Dynamic viscosity, } \mathrm{kg} \mathrm{s}^{-1} \mathrm{~m}^{-1} \\ \rho & \text { Density, } \mathrm{kg} \mathrm{m}^{-3} \\ \sigma & \text { Standard deviation, } \mathrm{K}\end{array}$

\section{Subscripts}

$\begin{array}{ll}4,5,9,13,16 & \text { Number of jets } \\ a v g & \text { Area-average value } \\ f & \text { Fluid } \\ i & \text { Inlet } \\ j & \text { Jet } \\ \text { max } & \text { Maximum value } \\ \text { mean } & \text { Mean value } \\ \bar{n} & \text { Vector in wall/plane normal direction } \\ o & \text { Outlet } \\ s & \text { Substrate }\end{array}$




\section{Introduction}

The growing demand for higher heat flux removal and the occurrence of hot spots from ultra-large scale integrated (ULSI) circuits of power electronics, concentrated photovoltaic, and highpower light emitting diodes (LEDs) have posed a major challenge to heat transfer researchers. The sensitivity, reliability, performance and efficiency of electronic devices are highly temperature dependent and a high temperature may lead to irreparable loss of electronics (Hamann et al. 2007). The increase in junction temperature decreases the life span of LEDs exponentially (Narendran and Gu 2005). The heat generated at the P-N junction is transferred to the substrate material which must be dissipated to allow proper functioning of electronics. These challenges have encouraged researchers to develop new, alternative cooling techniques at the mini- and micro-levels. As the air cooling techniques reach their limits, the liquid flow through parallel micro-channels provides a potential solution for the high heat-flux management of electronics. Tuckerman and Pease (1981) were the first to examine liquid-flow microchannel heat sinks. The liquid flows from one end to the other through narrow parallel channels, leaving higher temperatures at the inlet side and lower temperatures at the outlet side (Husain and Kim 2008a; Kawano et al. 1998; Knight et al. 1992; Liu and Garimella 2005; Toh et al. 2002; Qu and Mudawar 2002).

The hot-spot occurrence and high temperaturegradients lead to temperature non-uniformity on the heated surface and, consequently on the chip surface, inducing thermal stresses which eventually reduce the life span of the electronics. Jet impingement cooling offers an efficient solution for high heat-flux management of an entire surface as well as hot spots in power electronics with relatively more uniform temperature distribution over the chip surface. The recent developments in electronics cooling have directed researchers' endeavors towards achieving higher temperature uniformities as well as hot-spot management by the application of micro-jet impingements on the heated substrate (Lee and Vafai 1999; Wu et al. 1999). Wu et al. (1999) examined experimentally the heat transfer characteristics of $500 \mu \mathrm{m}$ and 550 $\mu \mathrm{m}$ single jets as well as a jet-array with $H$ ranging from 200-3000 $\mu \mathrm{m}$. They obtained an area-averaged heat transfer coefficient of $320 \mathrm{~W} / \mathrm{m}^{2} \mathrm{~K}$ for a $500 \mu \mathrm{m}$ single jet with $H=750 \mu \mathrm{m}$ at a pressure-drop of about $34.5 \mathrm{kPa}$. They also reported a higher cooling efficiency at a lower driving pressure, which decreased with further increase in the driving pressure. A comparative analysis of the microchannels and jet impingement cooling shows that the micro-channel cooling is preferable for a heated surface size smaller than $70 \mathrm{~mm} \times 70 \mathrm{~mm}$; and the jet impingement is comparable to or better than the micro-channel cooling for a large target plate with a proper arrangement of spent flow after impingements (Lee and Vafai 1999).

The potential of micro-jet impingement cooling in electronics has motivated researchers to examine micro-jet impingements cooling models both numerically and experimentally. Moreover, with the advent of advanced fabrication processes, the production of micro-scale jets has become more convenient than before (Jackson 2006). Wang et al. (2004) investigated experimentally single- and twophase flow micro-jet impingement cooling systems. They fabricated a single and multi-jet array with circular orifice diameters ranging from 40-76 $\mu \mathrm{m}$, which removes $90 \mathrm{~W}$ using a four-jet array at a flow rate of eight $\mathrm{ml} / \mathrm{min}$ with a temperature rise of 100 ${ }^{\circ} \mathrm{C}$ for a $1 \mathrm{~cm} \times 1 \mathrm{~cm}$ chip. Fabbri and Dhir (2005) examined impinging jet arrays in a circular pattern with three different radial and circumferential pitches of 1, 2 and $3 \mathrm{~mm}$. They investigated free jets of both water and FC-40 at Reynolds numbers ranging from 73-3813, and reported heat transfer coefficients ranging from $6-60 \mathrm{~kW} / \mathrm{m}^{2} \mathrm{~K}$. Sung and Mudawar (2006) proposed a hybrid cooling scheme for electronics cooling, which combines the cooling benefits of both microchannel and jet impingement. They carried out experimental and numerical analyses of slot-jet impingements in the microchannels which showed low rise and small temperature gradients across the surface.

Michna et al. (2009) experimentally investigated an array of micro-jets for stagnation heat transfer and obtained a maximum $11 \times 10^{6} \mathrm{~W} / \mathrm{m}^{2}$ heat flux for the rise of a surface temperature less than $30^{\circ} \mathrm{C}$. They observed that the Reynolds number, the Prandtl number, and the area ratio (total area of jets divided by the surface area) can have significant effects on heat transfer. Browne et al. (2010) reported micro-jet arrays of jet diameters $52 \mu \mathrm{m}$ and $112 \mu \mathrm{m}$ and a jet spacing of $250 \mu \mathrm{m}$ for heat transfer characteristics. They observed similar trends for micro-jet arrays for conventional- and macro-sized jet arrays. Husain et al. (2013a) investigated multiple micro-jet impingement heat sinks and carried out parametric optimization to find out optimal designs. In other studies, Husain et al. (2013b; 2013c) proposed turbulent and laminar flow numerical optimization models of jet impingement system for high power LEDs and 
ULSI circuits cooling, respectively. Wang and Peles (2014) investigated heat transfer enhancement through passive and active flow control by a jet issued from a micro pillar in a channel. The combined effect of micro-jet and pillar-enhanced spatially-averaged the Nusselt number by $80 \%$.

Macro-jet impingement cooling has been the subject of intense research with its applications in macro-heat sinks and turbomachines before the micro-jet impingement was applied in electronics cooling and micro-systems. The macro-jet impingement has a rich history, with most of the investigations based on air jet impingements (Garimella and Rice, 1995; Webb and Ma 1995; Womac et al. 1993; Womac et al. 1994;). Womac et al. (1993) proposed correlations for heat transfer and concluded that the $H / d$ ratio has a negligible effect on heat transfer, but an increase in velocity improves heat transfer. Garimella and Rice (1995) characterized a single submerged and confined jet for local heat transfer. They examined the effects of $d, H / d, l / d$, and the flow rate on heat transfer and proposed correlations based on the jet Reynolds number. Heo et al. (2011) investigated an inclined elliptic jet for cross-flow analysis through numerical methods, observing that the size of the recirculation region just upstream of the jet and the length of the potential core of the jet significantly affect the heat transfer process.

In view of the limited literature on the liquid flow multiple micro-jet impingement cooling and optimal jet-array configuration, the present study is devoted to investigating thermal performance and carries out parametric analyses of a liquid-flow multiple micro-jet impingements cooling model built on the backside of a silicon chip substrate. The effectiveness of several multi-jet configurations (ie. inline $2 \times 2,3 \times 3$, and $4 \times 4$ jets and staggered fivejet and 13-jet arrays with nozzle diameters of, 50 $\mu \mathrm{m}, 76 \mu \mathrm{m}$, and $100 \mu \mathrm{m})$ were analyzed at different flow rates to determine the thermal and pressuredrop characteristics.

\section{Mathematical Model and Simulation Strategy}

\subsection{Geometrical Model}

A multiple micro-jet impingements cooling model consisting of a fluid channel can be fabricated on a silicon substrate and micro-nozzles on a cover plate (Fig. 1). The design can be implemented at the backside of a silicon chip that emits heat flux from the integrated circuitry. The nozzles were designed on the substrate, and a water channel was created to allow liquid to pass through the nozzles as discussed by Wang et al. (2004). The liquid jets take the heat while striking at the heated surface. The flow then turns to the radial direction and reaches the outlet ports (Fig. 1). For a conservative analysis, the substrate on which these nozzles were designed was not taken for analysis, whereas the nozzles with a fluid channel and substrate base were included in the computational domain (Fig. 1(b)). The nozzles and outlet channel of the substrate can be fabricated separately and bonded together with epoxy to form the designed structure as discussed by Wang et al. (2004).

The overall dimensions of the micro-jet impingements domain (Fig. 1) are $10 \mathrm{~mm} \times 10 \mathrm{~mm}$ $\times 0.6 \mathrm{~mm}$. The thickness of the substrate base is 100 $\mu \mathrm{m}$ and the height of the liquid channel is $200 \mu \mathrm{m}$. The thickness of the nozzle plate in which multiple nozzles are designed is $300 \mu \mathrm{m}$. One half of the entire domain was taken as the computational domain due to the symmetry about the central plane (Fig. 1). The various parameters that affect the performance of the model are the thickness of the substrate base $\left(t_{s}\right)$, nozzle diameter $(d)$, length of the nozzle $(l)$, interjet spacing $(S)$, number of nozzles (n), channel height $(H)$, and the distribution of the jets (ie. the inline and staggered arrays) (Fig. 2). The geometric parameters, $l$ and $t_{s}$, were kept constant due to their unidirectional effects on the model performance (Liu and Garimella 2005; Michna et al. 2009), whereas the channel height $(H)$ was kept constant to keep concise the parametric investigations.

\subsection{Mathematical Model and Boundary Conditions}

Three-dimensional (3D) numerical analyses were performed for steady state incompressible laminar flow and conjugate heat transfer. The coolant, deionized ultra-filtered (DIUF) water, was allowed to flow through the micro-nozzles and channel. The governing equations of the model (viz. conservation of mass, momentum and energy) for fluid flow and conjugate heat transfer can be written in vector form as follows:

$\nabla \cdot\left(\rho_{f} \mathbf{V}\right)=0$

$\mathbf{V} \cdot \nabla\left(\rho_{f} \mathbf{V}\right)=-\nabla p+\nabla \cdot\left(\mu_{f} \nabla \mathbf{V}\right)$

For the fluid

$\mathbf{V} \cdot \nabla\left(\rho_{f} C_{p, f} T_{f}\right)=\nabla \cdot\left(k_{f} \nabla T_{f}\right)$

For the substrate

$\nabla \cdot\left(k_{s} \nabla T_{s}\right)=0$ 


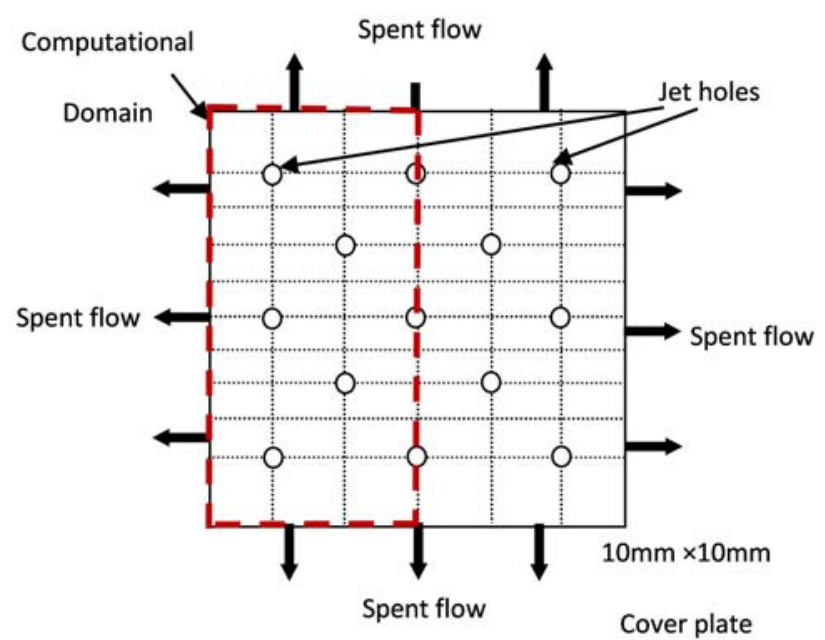

(a)

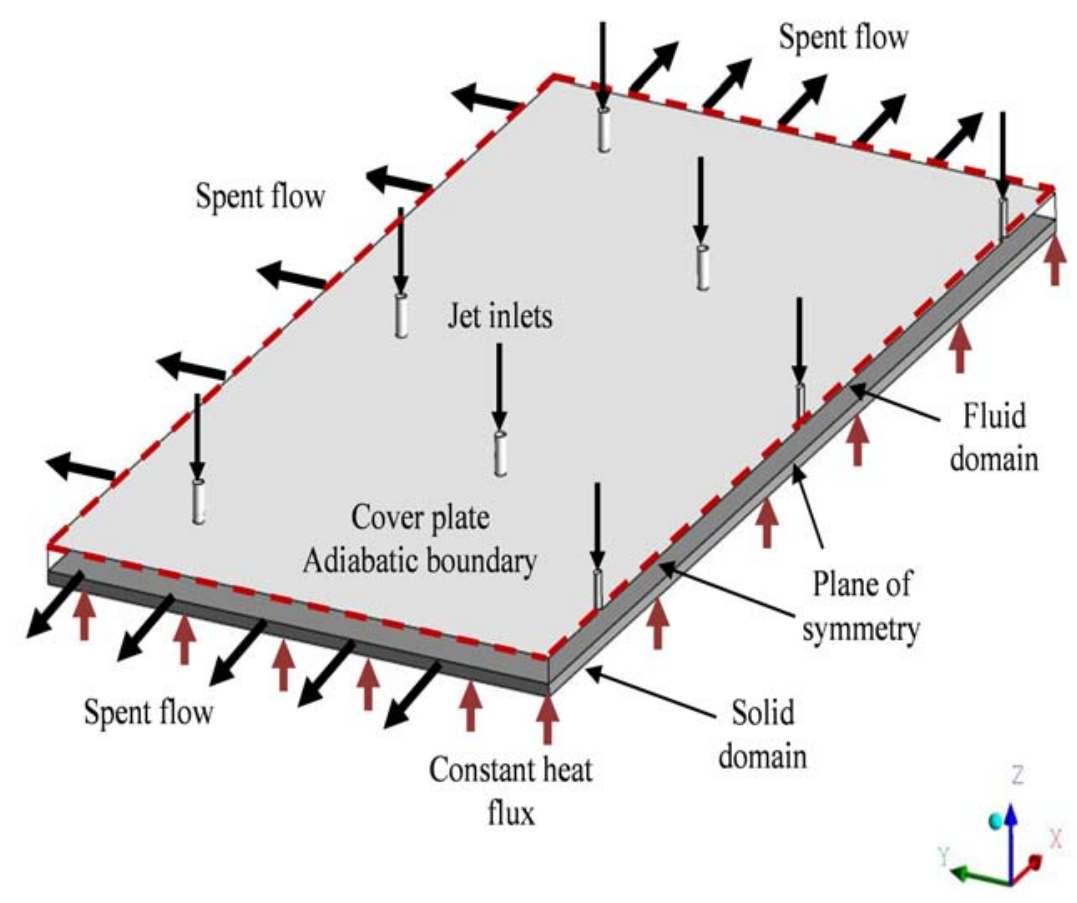

(b)

Figure 1. Schematic of multiple micro-jet-impingements model. (a) Cover plate with jet holes, and (b) Computational domain with boundary conditions.

The numerical simulations were carried out using a commercial computational fluid dynamics (CFD) code that employs coupled algebraic multigrid method (CFX Theory 2006; Raw 1996). The thermophysical properties (Incropera and DeWitt 2002) of the coolant DIUF water were allowed to vary with temperature and updated after every iteration to take micro-scale effects into account 

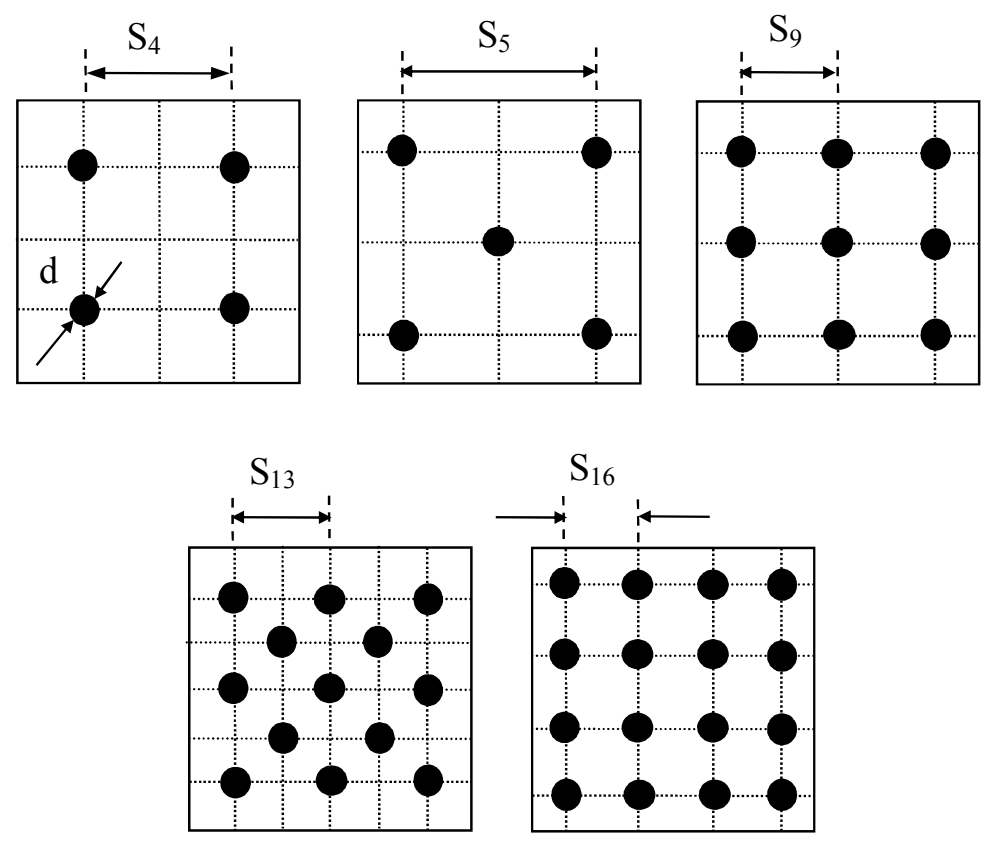

Figure 2. Various micro-jet configurations on the nozzle plate. (a) Inline $2 \times 2$ jet array, $\mathrm{S}_{4}=5 \mathrm{~mm},(\mathrm{~b})$ Staggered five-jet array, $S_{5}=7.0 \mathrm{~mm}$, (c) Inline $3 \times 3$ jet array, $S_{9}=3.5 \mathrm{~mm}$, (d) Staggered 13-jet array, $S_{13}=4$ $\mathrm{mm}$, and (e) Inline $4 \times 4$ jet array, $\mathrm{S}_{16}=2.5 \mathrm{~mm}$

(Herwig an Mahilikar 2006; Husain and Kim 2008b; Toh et al. 2002) during the iterative solution. A nonuniform hexahedral mesh was used in a specified computational domain to implement a numerical scheme (Fig. 3(a)). A high resolution scheme was applied to discretize advection terms of the governing equations. The top and bottom faces of the fluid domain interfaced with the substrate base and cover plate, respectively. The interior walls of the nozzles were assigned with adiabatic boundary conditions along with a no slip $(V=0)$ boundary condition. For conservative analysis, a constant heat flux was assigned as a heat source at the base of the substrate. A no-slip condition $(V=0)$ was applied at the interior walls of the nozzles and channel.

The thermal boundary conditions are:

$$
\begin{aligned}
& -k_{s} \frac{\partial T}{\partial z}=q \text { at } z=0,-\frac{l_{x}}{2} \leq x \leq \frac{l_{x}}{2}, \text { and } 0 \leq y \leq \frac{l_{y}}{2} \\
& -k_{s} \frac{\partial T}{\partial z}=0 \text { at }-\frac{l_{x}}{2} \leq x \leq \frac{l_{x}}{2}, \text { and } 0 \leq y \leq \frac{l_{y}}{2}
\end{aligned}
$$

$-k_{s} \frac{\partial T}{\partial \bar{n}}=0$ at the nozzle walls.

The boundary conditions on the symmetric plane are as follows:

$-k_{s} \frac{\partial T}{\partial \bar{n}}=0, v=0, \frac{\partial u}{\partial \bar{n}}=0, \frac{\partial p}{\partial \bar{n}}=0$, and $\frac{\partial w}{\partial \bar{n}}=0$

For the solid-liquid interface, the conditions are

$$
T_{s}=T_{f} \text { and }-k_{s} \frac{\partial T_{s}}{\partial \bar{n}}=-k_{f} \frac{\partial T_{f}}{\partial \bar{n}}
$$

The overall thermal resistance is defined as

$$
R_{t h}=\frac{\Delta T_{\max }}{q A_{s}}
$$

The maximum temperature-rise in the substrate is defined as

$$
\Delta T_{\max }=T_{s, \max }-T_{f, i}
$$



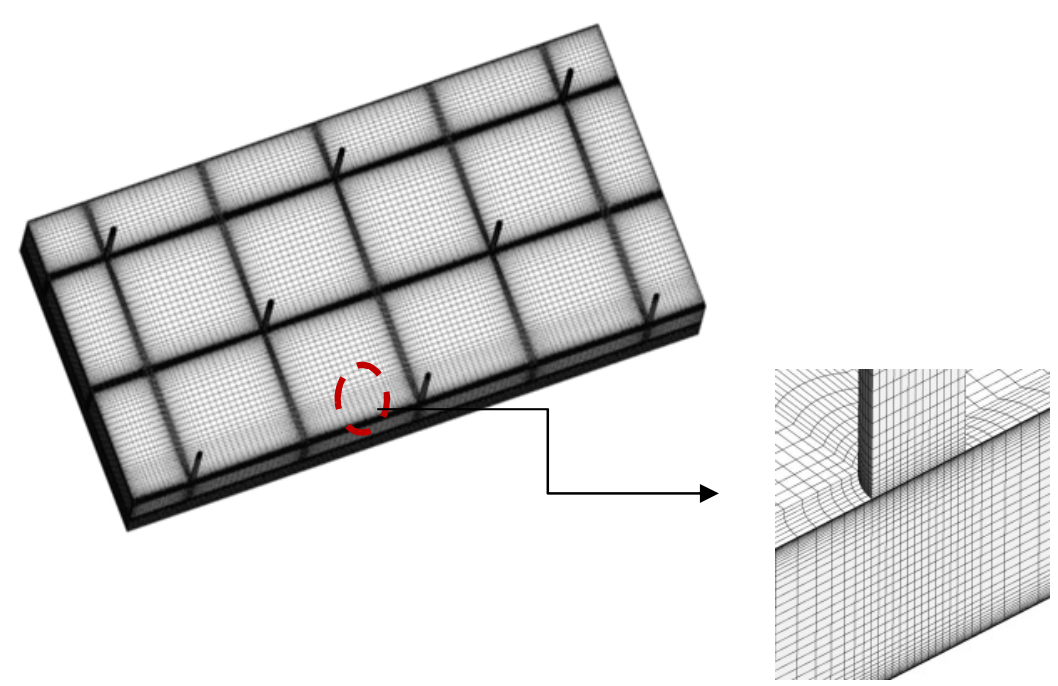

(a)

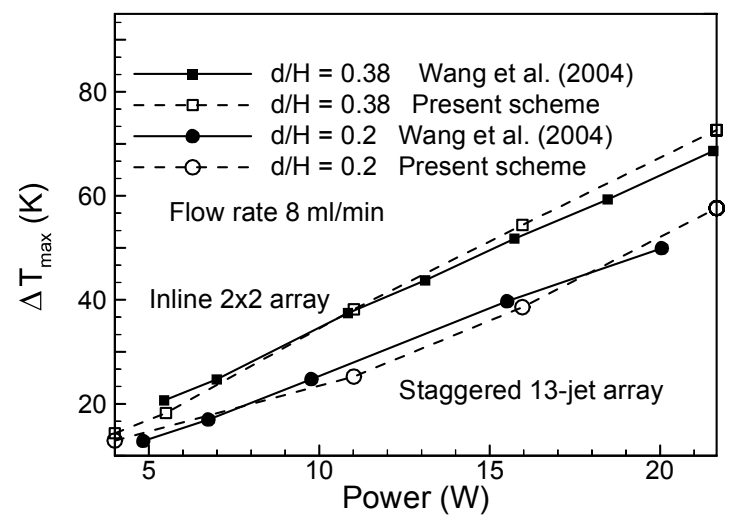

(b)

Figure 3. (a) Unstructured hexahedral grid, and (b) Comparison of numerical results with the results of Wang et al. (2004) for an inline $2 \times 2$ array and staggered 13-jet array.

The pumping power required to drive the fluid through the model can be evaluated as follows:

$$
P=\dot{V} \cdot \Delta p
$$

The pressure-drop is defined as:

$$
\Delta p=p_{o}-p_{i}
$$

The Reynolds number at the jet inlet was defined as:

$$
\operatorname{Re}=\frac{\rho V_{j, i} d_{n}}{\mu}
$$

where $V_{j, i}$ is the velocity at the inlet. The heat transfer coefficient was evaluated as

$$
h=\frac{q}{\left(T_{j, i}-T_{s}\right)}
$$

The coefficient of performance (COP) can be represented as the ratio of the heat flux to the pumping-power flux:

$$
C O P=\frac{q}{P^{\prime \prime}}
$$

where $P^{\prime \prime}$ is defined as $P^{\prime \prime}=\frac{P}{A_{s}}$. 
The degree of temperature uniformity at the impingement surface can be assessed in terms of the standard deviation $(\sigma)$ as follows:

Temperature uniformity,

$\sigma=\sqrt{\sum_{i=1}^{N}\left(T_{i}-T_{\text {mean }}\right)^{2}}$

where $\mathrm{T}_{1}, \mathrm{~T}_{2}, \mathrm{~T}_{3}$ $\mathrm{T}_{\mathrm{N}}$ are the temperatures at $\mathrm{N}$ sample points on the surface, and $\mathrm{T}_{\text {mean }}$ is the mean surface temperature. The temperature uniformity $(-\sigma)$ at the surface increased with a decreasing $\sigma$ value.

For a conservative analysis and simplification of the numerical model, radiation effects were ignored. The convergence was checked by the residual target of $10^{-6}$.

\section{Results and Discussion}

The grid dependency tests were carried out for both solid and liquid domains, and a grid of approximately 1,000,000 elements was used for a typical design of $d / H=0.33$ in an inline $2 \times 2$ jetarray. For a grid of 500,000 elements, the changes in pressure-drop $(\Delta p)$ and maximum temperature-rise $\left(\Delta T_{\max }\right)$ were more than $4 \%$, whereas the changes in $\Delta p$ and $\Delta T_{\max }$ were less than $2 \%$ for grid systems of $1,500,000$ and 2,000,000 elements. The validation of the present numerical scheme for a laminar flow in a channel and jet impingement, respectively, was reported in the authors' previous works (Husain and Kim 2008a; Husain et al. 2013a). Further validation of the micro-jet impingement system is presented in Fig. 3(b) for an inline $2 \times 2$ jet-array and staggered 13-jet array. The numerical reproduction of the data showed reasonable agreement with the experimental results reported by Wang et al. (2004).

The temperature distribution and uniformity on the heated surface were presented by local temperature plots and the overall standard deviation of the temperature at the solid-fluid interface (Fig 3). Figure 4 shows the temperature distribution at the impingement surface at a constant mass flow rate. A substantially small temperature range and higher temperature uniformity were observed for the design with the higher number of jets. The high temperature zones were present in the interjet spacings away from the stagnation region. With the increased number of jets, the interjet spacing decreased, resulting in high fluid mixing and the occurrence of secondary flow. The strength of the secondary flow increased with the further decrease in the interjet spacing. The increase in number of impingements resulted in increased temperature uniformity and decreased temperature-gradient monotonously. The maximum-temperature-rise increases with the increase in jet diameter to the channel height ratio (Fig. 5) shows the temperature distribution and uniformity at the impingement surface for $d / H=$ $0.2-0.5$ and $\dot{m}=5.32 \times 10^{-4} \mathrm{~kg} . \mathrm{s}^{-1}$. At a constant mass flow rate, the jet velocity and jet Reynolds number decreased with the increase in $\mathrm{d} / \mathrm{H}$ ratio. The reduced jet Reynolds number led to a decrease in the heat transfer coefficient and an increase in the $\Delta T_{\max }$ (Fig. 5).

The performance of the various jet configurations (ie. inline $2 \times 2,3 \times 3$, and $4 \times 4$ jets and staggered five-jet and 13-jet arrays) were analyzed for the area-averaged heat transfer coefficient $\left(h_{\text {avg }}\right), \Delta T_{\max }$, and pressure drop at a constant mass flow rate of $1.33 \times 10^{-4} \mathrm{~kg} \mathrm{~s}^{-1}$ for $d / H=$ $0.25, d / H=0.33$ and $d / H=0.5$ (Fig. 6). At a constant mass flow rate, increasing the number of jets led to decreasing the mass flow rate per jet and the jet Reynolds number. In general, increasing the number of jets decreased the $\Delta T_{\max }$ except for the increase in number of jets from 4 to 5 (Fig. 6(a)) where interjet spacing increased significantly even with the increase in the number of jets as shown in Figure 2's configuration. The increase in interjet spacing developed high temperature zones between the adjacent jets. The heat transfer coefficient and the pressure-drop decreased consistently with an increase in the number of jets, showing the weakened effects of stagnation heat transfer due to the decrease in jet velocity for all parameters explored in the present study (Figs. 6(b) and (c)). The increase in the number of jets significantly decreased the $\Delta T_{\max }$ and the pressure drop.

The inline $4 \times 4$ jet array design was selected for further analysis of performance parameters. The designs with lower $\Delta T_{\max }$ were achieved with higher pressure-drop penalties (Fig. 7). In view of the limited pumping powers available at the microlevel and to maintain flow within the laminar regime, the range of the mass flow rates was set to vary from $1.33 \times 10^{-4}$ to $7.98 \times 10^{-4} \mathrm{~kg} \mathrm{~s}^{-1}$. The $\Delta T_{\max }$ and pressure-drop change nonlinearly with the $d / H$ ratio and mass flow rate (Fig. 7 (c)).

The higher jet velocities, which stem from the increased mass flow rate, increased the local as well as the area-averaged heat transfer coefficients, which finally decreased the $\Delta T_{\max }$. With increasing 
(a)



(b)

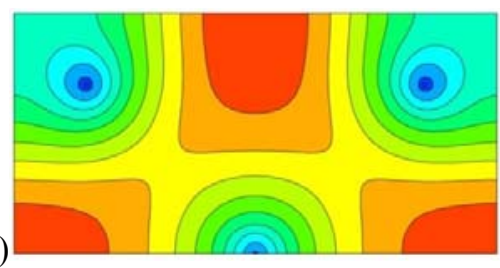

(c)

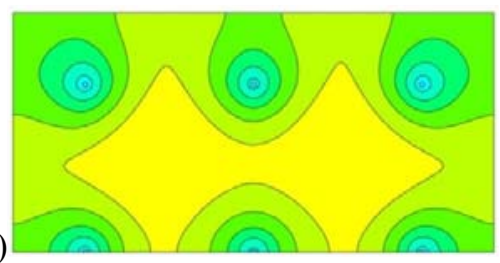

(d)

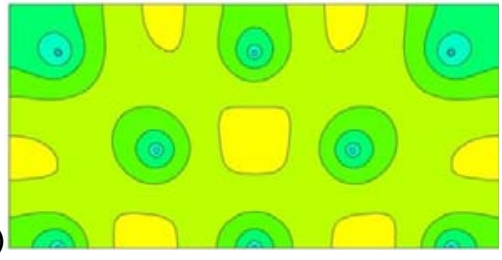

(e)


Figure 4. Temperature distribution and uniformity $(-\sigma)$ on the jet impingement surface for various microjet configurations at $d / H=0.5$ and a mass flow rate of $1.33 \times 10^{-4}$ : (a) Inline $2 \times 2$ jet array, $-\sigma=-9.81$, (b) Staggered five-jet array, $-\sigma=-13.37$, (c) Inline $3 \times 3$ jet array, $-\sigma=-6.6$, (d) Staggered 13-jet array, $-\sigma=-5.24$, and (e) Inline $4 \times 4$ jet array, $-\sigma=-3.4$.

coolant flow rates, the $\Delta T_{\max }$ decreased and pressure drop increased consistently, but higher coefficient of performance (COP) values were associated with the low flow rates (Table 1). Although an increase of mass flow rate decreased the COP of the model, it improved the temperature uniformity $(-\sigma)$ at the heated surface. Table 1 highlights the conflicting nature of the COP and the temperature uniformity with the increasing mass flow rate for an inline $4 \times 4$ jets array. The functional characteristics between the $\Delta T_{\max }$ and pressure drop showed that a higher $\mathrm{d} / \mathrm{H}$ ratio gives a lower maximum-temperature rise, lower temperature uniformity and pressure drop but a higher COP, making it advantageous within the range investigated in this study. 


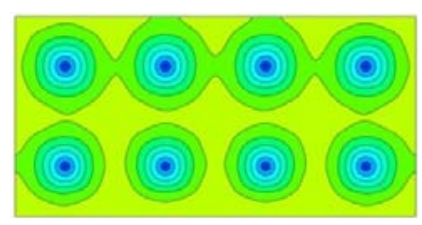

(a)

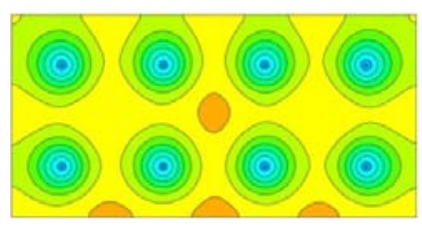

(b)

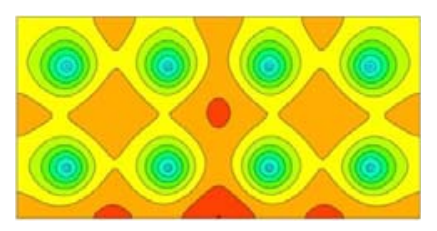

(c)

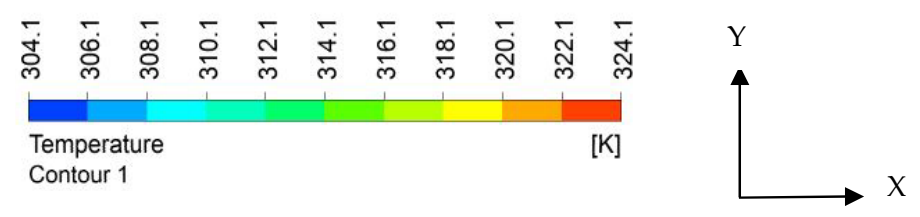

Figure 5. Temperature distribution and uniformity $(-\sigma)$ on the jet impingement surface for inline $4 \times 4$ jet array at a mass flow rate of $5.32 \times 10^{-4} \mathrm{~kg} / \mathrm{s}$. (a) $d / H=0.25,-\sigma=-2.57$, (b) $d / H=0.33,-\sigma=-2.71$, and (c) $d / H$ $0.5,-\sigma=-2.66$

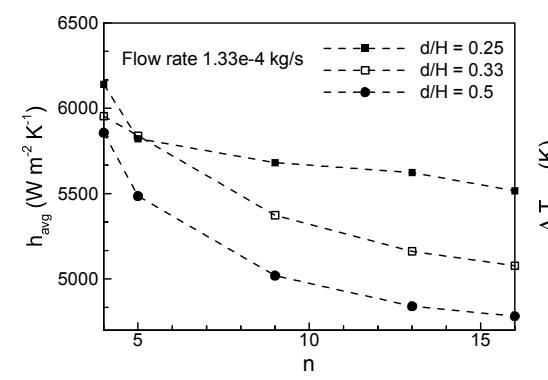

(a)

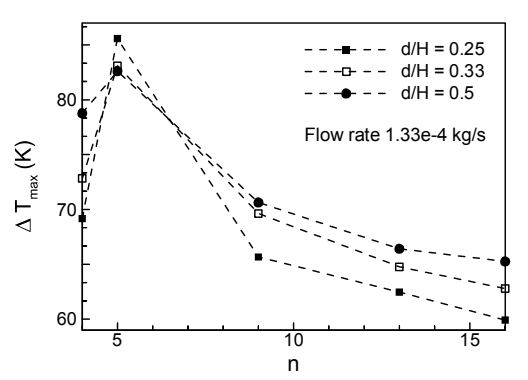

(b)

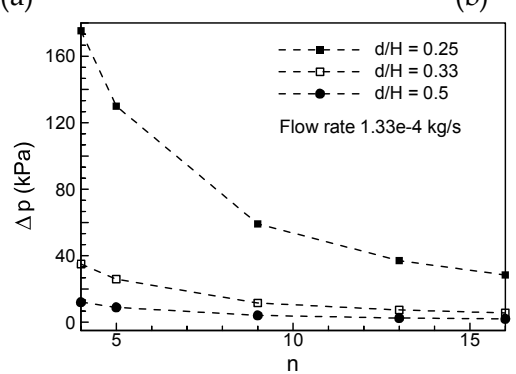

(c)

Figure 6. Effect of the micro-jet configuration and number of jets on thermal performance at a mass flow rate of $1.33 \times 10^{-4} \mathrm{~kg} / \mathrm{s}$ and $d / H=0.25-0.5$. (a) Area-averaged heat transfer coefficient $\left(h_{\text {avg }}\right)$, (b) Maximum temperature-rise $\left(\Delta T_{\max }\right)$, and (c) Pressure drop $(\Delta p)$. 


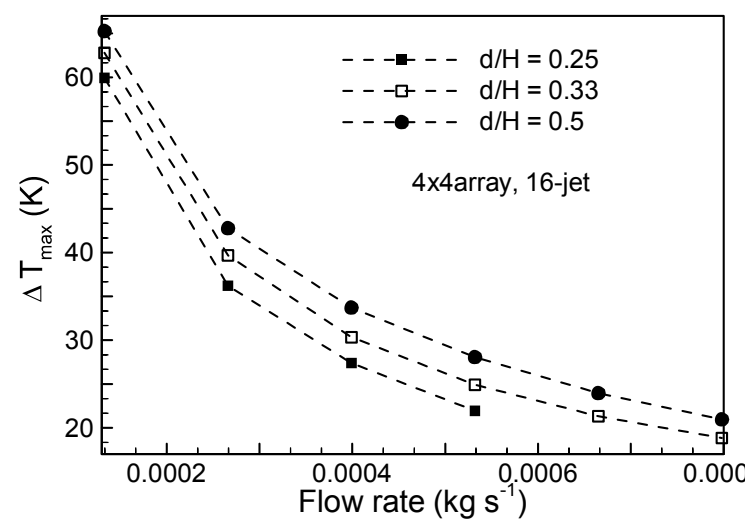

(a)



(b)

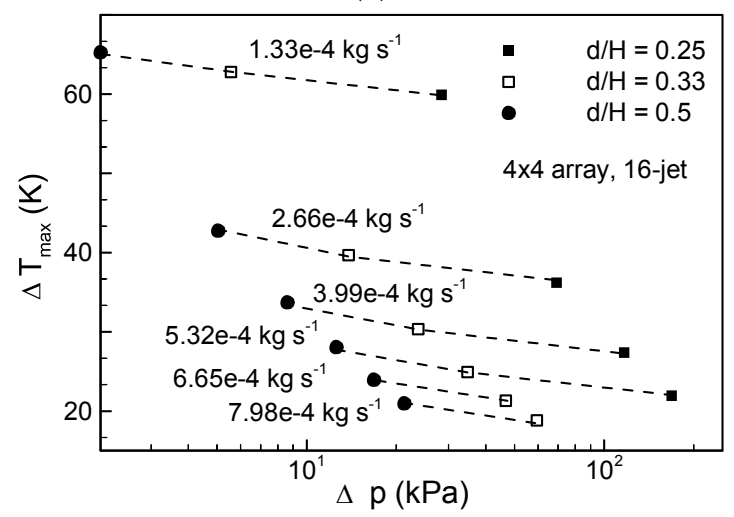

(c)

Figure 7. Effect of the mass flow rate on the maximum temperature rise $\left(\Delta T_{\max }\right)$ and pressure $\operatorname{drop}(\Delta p)$ characteristics for an inline $4 \times 4$ jet array configuration. (a) Maximum temperature rise $\left(\Delta T_{\max }\right)$, (b) Pressure $\operatorname{drop}(\Delta p)$, and (c) Maximum temperature rise $\left(\Delta T_{\max }\right)$ versus pressure drop $(\Delta p)$.

The jet impingement flow field can be assumed to be laminar for a jet Reynolds number $<1000$ (Zuckerman and Lior 2006). The increase in the jet Reynolds number caused an increase in the stagnation heat transfer coefficient, which consequently increased the area-averaged heat coefficient of the jet impingements. The areaaveraged heat transfer coefficient increased monotonously with the increasing jet Reynolds number (Fig, 8(a)) for an inline $4 \times 4$ jet array with $d / H=0.33-0.5$, resulting in a consistent decrease in the thermal resistance $\left(R_{t h}\right)$. The pressure drop 


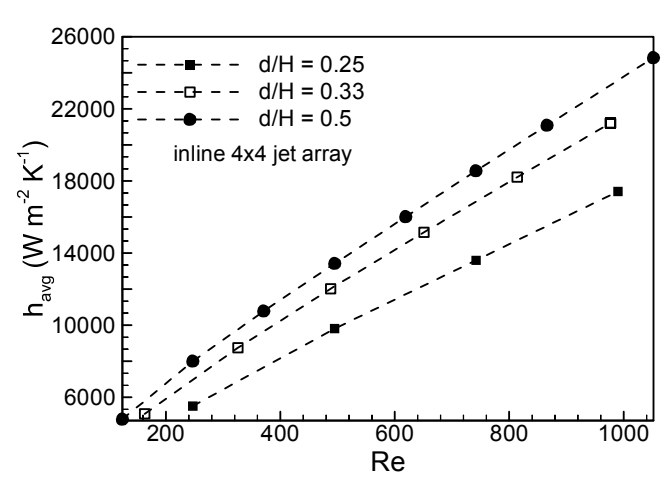

(a)

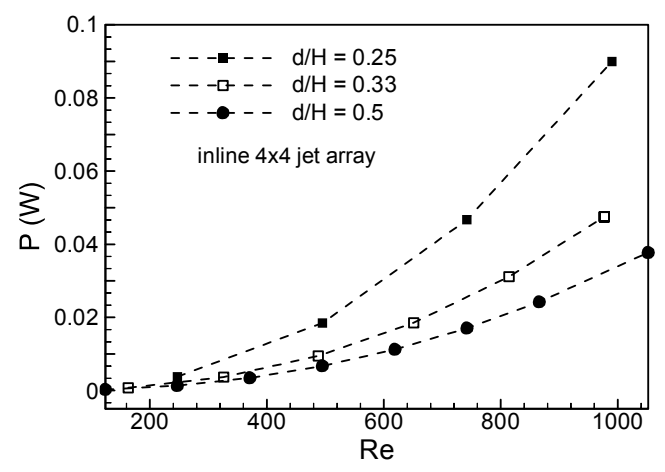

(c)

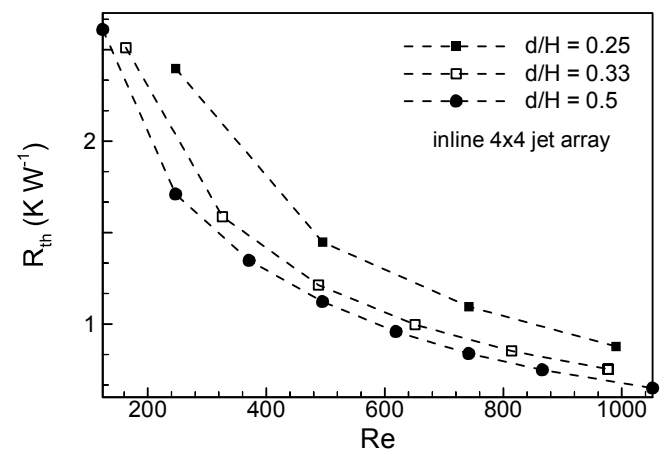

(b)



(d)

Figure 8. Characteristic variation of area-averaged heat transfer coefficient $\left(h_{\text {avg }}\right)$, thermal resistance $\left(R_{t h}\right)$, and pumping power $(P)$ with Reynolds number $(R e)$. (a) Area-averaged heat transfer coefficient $\left(h_{\text {avg }}\right)$ versus Reynolds number $(\mathrm{Re}),(\mathrm{b})$ Thermal resistance $\left(R_{t h}\right)$ versus Reynolds number $(\mathrm{Re}),(\mathrm{c})$ Pumping power $(\mathrm{P})$ versus Reynolds number $(\mathrm{Re})$, and $(\mathrm{d})$ Thermal resistance $\left(\mathrm{R}_{t h}\right)$ versus pumping power $(\mathrm{P})$.

Table 1. Maximum temperature rise $\left(\Delta T_{\max }\right)$, coefficient of performance $(\mathrm{COP})$, and temperature uniformity $(-\sigma)$ of a multiple micro-jet-impingements cooling model with an inline $4 \times 4$ jet array at various mass flow rates.

\begin{tabular}{|c|c|c|c|c|c|c|c|c|c|}
\hline \multirow{2}{*}{$\begin{array}{c}\text { Mass } \\
\text { flow rate } \\
\left(\mathrm{kg} \mathrm{s}^{-1}\right)\end{array}$} & \multicolumn{3}{|c|}{$\Delta \mathrm{T}_{\max }(\mathrm{K})$} & \multicolumn{3}{|c|}{ COP } & \multicolumn{3}{|c|}{$-\sigma(K)$} \\
\hline & $\begin{array}{c}d / H= \\
0.25\end{array}$ & $\begin{array}{c}d / H= \\
0.33\end{array}$ & $\begin{array}{c}d / H= \\
0.5\end{array}$ & $\begin{array}{c}d / H= \\
0.25\end{array}$ & $\begin{array}{c}d / H= \\
0.33\end{array}$ & $\begin{array}{c}d / H= \\
0.5\end{array}$ & $\begin{array}{c}d / H= \\
0.25\end{array}$ & $\begin{array}{c}d / H= \\
0.33\end{array}$ & $\begin{array}{c}d / H= \\
0.5\end{array}$ \\
\hline $1.33 \mathrm{e}-4$ & 59.92 & 92.79 & 65.26 & 6603 & 33672 & 92439 & -3.76 & -3.58 & -3.40 \\
\hline $2.66 \mathrm{e}-4$ & 36.21 & 39.68 & 42.76 & 1355 & 6777 & 18607 & -3.15 & -3.09 & -2.96 \\
\hline $3.99 \mathrm{e}-4$ & 27.38 & 30.34 & 33.70 & 535 & 2636 & 7251 & -2.85 & -2.87 & -2.79 \\
\hline $5.32 \mathrm{e}-4$ & 21.95 & 24.92 & 28.07 & 278 & 1349 & 3725 & -2.57 & -2.71 & -2.66 \\
\hline 6.65 e-4 & - & 21.32 & 23.95 & - & 803 & 2229 & - & -2.57 & -2.54 \\
\hline 7.98 e-4 & - & 18.84 & 20.96 & - & 525 & 1468 & - & -2.45 & -2.44 \\
\hline
\end{tabular}


increased consistently with the increase in the Reynolds number due to the higher friction losses in the impingement system, consequently resulting in a higher pumping power $(\mathrm{P})$ to drive the fluid through the domain (Fig. 8(c)). The velocity of the fluid passing through the nozzles increased with the decrease in $d / H$ ratio at the constant jet Reynolds number, which resulted in an increase in the pressure drop and, consequently, an increase in pumping power (Fig. 8(c)). On the other hand, higher jet velocities increased the stagnation as well as area-averaged heat transfer coefficient (Martin 1997), which consequently reduced the convective thermal resistance of the system. The two performance parameters of thermal resistance and pumping power showed a conflicting nature with the change of the design variable or the Reynolds numbers (Fig. 8(d)). The information in Fig. 8(d) suggests that lower thermal resistance can be obtained at the expense of higher pumping power and vice versa. The optimum designs can be obtained from the trade-off curves based on the available pumping power and required thermal resistance.

\section{Summary and Conclusion}

This study examined the thermal and pressuredrop characteristics of a silicon-based micro-jet impingement cooling model for electronic cooling through 3D numerical analyses. The different micro-jet configurations (ie. inline $2 \times 2,3 \times 3$, and 4 $\times 4$ jets and staggered five-jet and 13-jet arrays with various jet diameter-to-channel height ratios) were examined to determine the temperature and pressure drop, heat transfer coefficient, thermal resistance and pumping power characteristics for a range of flow rates and Reynolds numbers. The convection and radiation at the outer walls were neglected to maintain a conservative thermal analysis. The multiple impingements produced higher temperature uniformity on the heated surface for the jets of all diameters. For the constant flow rates across the domain, the increase in jet diameter increased the maximum-temperature rise in the substrate. In general, the temperature rise and pressure drop decreased with an increase in number of jets. The increase in flow rates, though, increased the temperature uniformity but decreased the coefficient of performance of the model. The thermal resistance and pumping power showed a conflicting nature with the design parameters and jet Reynolds numbers.

\section{Acknowledgment}

The authors would like to acknowledge the support of Sultan Qaboos University through an internal research grant (IG/ENG/MEID/14/03) for conducting this research.

\section{References}

Browne EA, Michna GJ, Jensen MK, Peles Y (2010), Experimental investigation of single-phase microjet array heat transfer. Journal of Heat Transfer 132: 041013-19.

CFX-11.0 (2006), Solver Theory, ANSYS Europe Ltd.

Fabbri M, Dhir VK (2005), Optimized heat transfer for high power electronic cooling using array of microjets. Journal of Heat Transfer 127: 760-769.

Garimella SV, Rice RA (1995), Confined and submerged liquid jet impingement heat transfer. ASME Journal of Heat Transfer 117(4): 871-877.

Hamann HF, Weger A, Lacey JA, Hu Z, Bose P, Cohen E, Wakil J (2007), Hotspot-limited microprocessors: direct temperature and power distribution measurements. IEEE Journal of SolidState Circuits 42(1): 56-65.

Heo MW, Lee KD, Kim KW (2011), Optimization of an inclined elliptic impinging jet with cross flow for enhancing heat transfer. Heat and Mass Transfer 47: 731-742.

Herwig H, Mahulikar SP (2006), Variable property effects in single-phase incompressible flows through microchannels. International Journal of Thermal Science 45: 977-981.

Husain A, Kim KY (2008a), Optimization of a microchannel heat sink with temperature dependent fluid properties. Applied Thermal Engineering 28: 1101-1107.

Husain A, Kim KY (2008b), Shape optimization of micro-channel heat sink for micro-electronic cooling. Components and Packaging Technologies, IEEE Transactions 31(2): 322-330.

Husain A, Kim JH, Kim KY (2013a), Thermal performance of a silicon-based multiple micro-jet impingement heat sink, Proceedings of ASME 2013 International Technical Conference and Exhibition on Packaging and Integration of Electronic and photonic Microsystems, InterPACK2013, July 16-18, Burlingame, CA, USA, IPACK2013-73063.

Husain A, Kim SM, Kim JH, Kim KY (2013b), Thermal performance analysis and optimization of multiple micro-jet impingements cooling of high power LEDs. Journal of Thermophysics and Heat Transfer 27(2): 235-245. 
Husain A, Kim SM, Kim KY (2013c), Performance analysis and design optimization of micro-jet impingement heat sink. Heat and Mass Transfer 49(11): 1613-1624.

Incropera FP, DeWitt DP (2002), Fundamentals of heat and mass transfer. New York, NY: John Wiley and Sons, Inc.

Jackson MJ (2006), Microfabrication and nanofabrication. Boca Raton, FL: CRC Press.

Kawano K, Minakami K, Iwasaki H, Ishizuka M (1998), Development of micro channels heat exchanging. In: Nelson RA, Jr., Swanson LW, Bianchi MVA, and Camci C (Eds), Application of Heat Transfer in Equipment Systems and Education. ASME, New York, HTD-361-3/PID-3: 173-180.

Knight RW, Hall DJ, Goodling JS, Jaeger RC (1992), Heat sink optimization with application to microchannels. IEEE Transactions in Components, Hybrids, and Manufacturing Technologies 15(5): 832-842.

Lee DY, and Vafai K (1999), Comparative analysis of jet impingement and microchannel cooling for high heat flux applications. International Journal of Heat and Mass Transfer 42: 1555-1568.

Liu D, Garimella SV (2005), Analysis and optimization of the thermal performance of microchannel heat sinks. International Journal of Numerical Methods for Heat and Fluid Flow 15(1): 726.

Martin H (1997), Heat and mass transfer between impinging jets and solid surfaces. Advances in Heat Transfer 13: 1-60

Michna GJ, Browne EA, Peles Y, Jensen MK (2009), The effect of area ratio on microjet array heat transfer. International Journal of Heat and Mass Transfer 54: 1782-1790.

Narendra N, Gu Y (2005), Life of LED-based white light sources. IEEE/OSA (Optical Society of America) Journal of Display Technology 1(1): 167171.

Qu W, Mudawar I (2002), Experimental and numerical study of pressure drop and heat transfer in a single-phase micro-channel heat sink. International Journal of Heat and Mass Transfer 45: 2549-2565.
Raw MJ (1996), Robustness of coupled algebraic multigrid for the Navier-Stokes equations. In: 34th Aerospace and Sciences Meeting and Exhibit, January 15-18, AIAA 96-0297, Reno, NV.

Sung MK, Mudawar I (2006), Experimental and numerical investigation of single-phase heat transfer using hybrid jet impingement/microchannel cooling scheme. International Journal of Heat and Mass Transfer 49: 682-694.

Toh KC, Chen XY, Chai JC (2002), Numerical computation of fluid flow and heat transfer in microchannels. International Journal of Heat and Mass Transfer 45: 5133-5141.

Tuckerman DB, Pease RFW (1981), Highperformance heat sinking for VLSI. IEEE Electronic Device Letters 2(5): 126-129.

Wang Y, Peles, Y (2014), An experimental study of passive and active heat transfer enhancement in microchannels. Journal of Heat Transfer 136: 031901-111.

Wang EN, Zhang L, Jiang L, Koo JM, Maveety JG, Sanchez EA, Goodson KE, Kenny TW (2004), Micromachined jets for liquid impingement cooling of VLSI chips. Journal of Microelectromechanical Systems 13(5): 833-842.

Webb BW, Ma CF (1995), Single-phase liquid jet impingement heat transfer. Advances in Heat Transfer 26: 105-217.

Womac DJ, Ramadhdhyani S, Incropera FP (1993), Correlating equations for impingement cooling of small heat sources with single circular liquid jets ASME. Journal of Heat Transfer 115(1): 106-116.

Womac DJ, Incropera FP, Ramadhdhyani S (1994), Correlating equations for impingement cooling of small heat sources with multiple circular liquid jets. ASME Journal of Heat Transfer 116(2): 482486.

Wu S, Mai J, Tai YC, Ho CM (1999), Micro heat exchanger by using MEMS impinging jets. In: Proc. of the $12^{\text {th }}$ IEEE International Conference on Micro Electro Mechanical Systems (MEMS), Orlando, FL, 171-176.

Zuckerman N, Lior N (2006), Jet impingement heat transfer: Physics, correlations, and numerical modeling. Advances in Heat Transfer 39: 565-631. 